
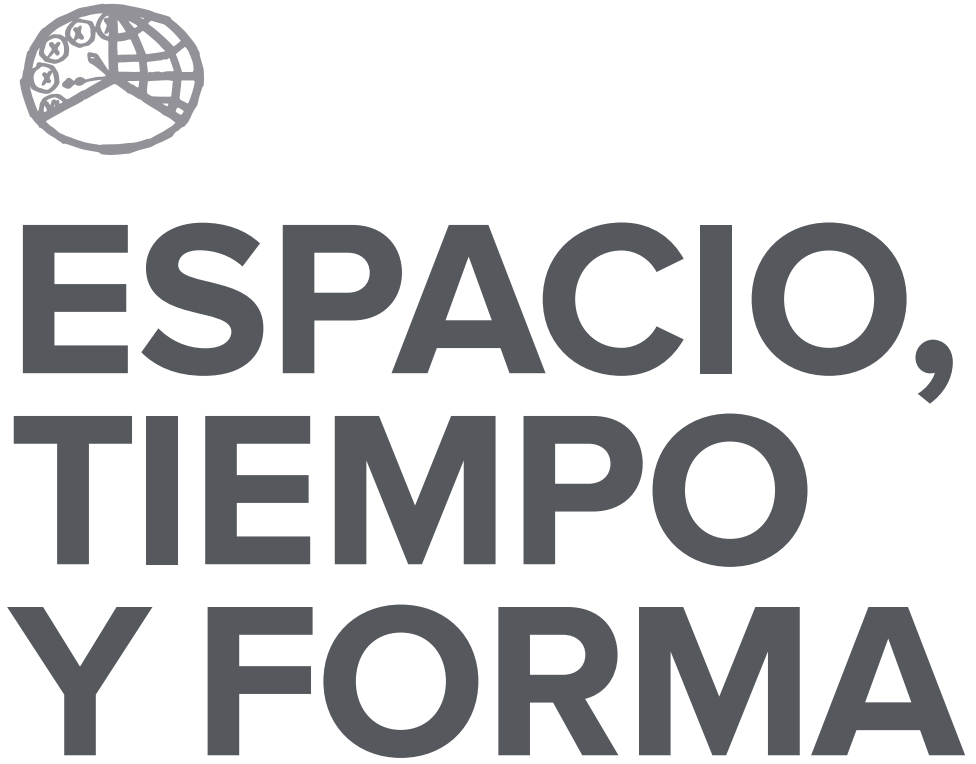

AÑO 2020

ISSN 0214-9745

E-ISSN 2340-1362

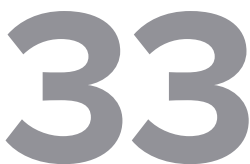

SERIE III HISTORIA MEDIEVAL

REVISTA DE LA FACULTAD DE GEOGRAFÍA E HISTORIA 



\section{ARTÍCULOS · ARTICLES}





\title{
LAS FORMAS DE LA VIOLENCIA \\ ENTRE FRAILES. EL TESTIMONIO \\ DE FRAY UBERTINO DE CASALE
}

\section{FORMS OF VIOLENCE BETWEEN FRIARS. UBERTINO OF CASALE'S TESTIMONY}

\author{
Paula Castillo ${ }^{1}$ \\ Recepción: 2019/12/21 C Comunicación de observaciones de evaluadores: 2020/01/28 . \\ Aceptación: 2020/01/30 \\ DOI: http://dx.doi.org/10.5944/etfiii.33.2020.26258
}

\section{Resumen}

El movimiento iniciado por Francisco de Asís ha sido asociado a lo largo del tiempo a un mensaje cristiano de paz, tolerancia y misericordia. Sin embargo, en la historia de la Orden encontramos diversos testimonios que refieren a situaciones turbulentas. El objetivo de este trabajo es ahondar sobre las diferentes formas en que se manifestaron la violencia y el conflicto entre hermanos a partir de un testimonio: el que desplegó fray Ubertino de Casale en los debates del concilio de Vienne entre I3I0 y I3I2. De este modo, se realizará una recolección de las diversas situaciones denuncias en torno a tópicos específicos, a la vez que se analizará con una mirada de análisis del discurso cuáles son los recursos que se despliegan a la hora de representar la violencia.

\section{Palabras clave}

Violencia; conflicto; frailes; Orden de los frailes Menores; Ubertino de Casale.

\section{Abstract}

The movement initiated by Francis of Assisi has been identified over time with a Christian message of peace, tolerance and compassion. However, we find various testimonies that refer to turbulent situations in the history of the Order. The purpose of this study is to delve into the various means by which violence and conflict between friars themselves have surfaced. We will focus on friar Ubertino of Casale's testimony in the debates of the Council of Vienne between I3IO and I3I2.

1. Universidad Nacional de Tres de Febrero (UNTREF) (Argentina). C.e.: castillompaula@gmail.com 
Through his testimony, we will identify a series of complaints by way of specific stereotypes, and through the use of discourse analysis we will unveil the elements utilized in order to represent violence.

\section{Keywords}

Violence; Conflict; Friars; Order of Friars Minor; Ubertino of Casale. 
Contra omnem caritatis humanitatem crudelissime interempti...

\section{INTRODUCCION}

Hacia inicios del siglo XIV la Orden de los frailes Menores atravesaba una situación de extrema tensión entre sus integrantes. La problemática estaba asociada, en última instancia, a desacuerdos creados en torno a la identidad propia franciscana y el legado de su iniciador. Tal es así que en 1309 el papa Clemente V creó una comisión cardenalicia para afrontar el estado de la misma y llegar a una solución con respecto a: la observancia de la Regla, la postura respecto de las doctrinas de fray Pedro Olivi, la situación de los frailes de Provenza y la infiltración de la secta del spiritus libertatis en la Orden².

A la comisión asistieron representantes de cada uno de los grupos que se enfrentaban, así, por parte de los llamados de la «comunidad» se presentaron el ministro general Gonzalo Balboa, que fue asistido, en primera instancia, por cuatro maestros en teología: Vital du Four, provincial de Aquitania; Alejandro de Alejandría, ministro provincial, que luego llegará a general; fray Gil, de la provincia de Francia, y fray Martín, provincial de Inglaterra³. Luego se sumarán a su grupo Raimundo de Fronsac y Bonagracia de Bérgamo. En nombre del grupo que posteriormente fue apodado «espiritual» se apersonaron fray Raiumundo Gaufridi, ex ministro general; Raimundo de Cignac, ex provincial de Aviñón; Guillermo de Cornillon, custodio de Arlés; Guillermo de Ganges, lector de Béziers y Ubertino de Casale, entre los principales ${ }^{4}$. Dentro de los debates suscitados en el marco de dicha comisión son de carácter preponderante los planteos expuestos por Ubertino de Casale en sus opúsculos. En primera instancia, porque él, como asesor del cardenal Napoleón Orsini, se constituyó como uno de los paladines defensores de la postura de los rigoristas y de fray Pedro Olivi sobre el usus pauper; y en segunda instancia, porque es una documentación que a partir de diversas ediciones -de fines del siglo XIX e inicios del XX- se encuentra disponible y escasamente trabajada.

Las circunstancias del debate y las inesperadas muertes de varios de los defensores de los rigoristas devinieron en que Ubertino, quien había sido convocado principalmente para la discusión respecto a la secta spiritus libertatis-zanjada

2. Merlo, Giovanni Grado: Nel nome di san Francesco. Padova, Editrici Francescane, 2012, p. 253-4.

3. Gratien de París: Historia de la fundación y evolución de la Orden de los frailes menores en el siglo XIII. Buenos Aires, Dedebec, 1947 [1 ed. 1926], p. 403. En la segunda etapa del debate llegarán catorce frailes teólogos más: Protesta de Bonagrazia, en ALKG, III, 1887, p. 39. ALKG: Archiv Für Literatur-und Kirchengeschichte des Mittelalters.

4. Cabe señalar aquí que ambos nombres que se dan a los grupos son arbitrarios y colocados por historiadores a posteriori. En ambos casos, hay que tener presente que involucran a sujetos con diversas trayectorias individuales. Sobre esto reflexionaron varios historiadores, véase: BURR, David: The spiritual franciscans: from protest to persecution in the century after saint Francis. Pennsylvania, The Pennsylvania State University Press, 2001. 
rápidamente ya que nadie dudaba de su carácter herético- tuviera que afrontar prácticamente solo a los frailes de la comunidad desde mediados de I3Io. Por esto, los opúsculos polémicos de la llamada Magna disceptatio son la fuente principal para reconstruir dichos debates y analizar los argumentos de ambos grupos.

No es nuestro interés abocarnos al análisis de los debates en sí mismos ${ }^{5}$, sino pensar la problemática de la conflictividad entre hermanos de la misma orden, la forma en que se dieron dichos conflictos y la manera en que se representaron ${ }^{6}$. Cuando hablamos de representaciones se está haciendo referencia a un grupo de prácticas culturales que se apropian y dotan de un sentido a un entorno específico. Además, nos hacen presentes todo aquello que se encuentra ausente? Las prácticas discursivas y las practicas no discursivas son ambas reales. Las primeras son también parte de la realidad, es decir fragmentos de ella ${ }^{8}$. Analizar las representaciones es, por lo tanto, analizar las relaciones de fuerza que se estaban disputando en el interior de la Orden'.

De esta manera, el objetivo de este artículo es, en primer lugar, reponer las situaciones que hoy caracterizaríamos de violentas que denuncia el fraile frente a los hermanos de la comunidad y frente al mismísimo pontífice. En segundo lugar, analizar la forma en que el autor plasma este tipo de noticias y conflictos a la hora de denunciarlos.

\section{UBERTINO DE CASALE}

Hacia I273 habría ingresado a la Orden de los Menores fray Ubertino de Casale en la provincia de Génova, prontamente fue enviado a París en donde permaneció nueve años. En I285 fue destinado a la Toscana y hasta I289 ejerció el oficio de lector en Florencia, en donde conoció a fray Pedro Olivi quien será su gran maestro. Este fue un encuentro que marcará su pensamiento ${ }^{\mathrm{IO}}$ ya que a lo largo de su vida se

5. Véase el trabajos como: LAMBERTINI, Roberto: «Ubertino contro la comunità», Ubertino da Casali. Atti del XLI Convegno della Società internazionale di Studi Francescani e del Centro interuniversitario di studi francescani Assisi 18-20 ottobre 2013, Spoleto, Centro Italiano di Studi sull`Alto Medioevo, 2014, pp. 299-323; CusATo, Michael: «Whence «The Community»?», Franciscan Studies, 2002, 60, pp. 39-92. Para la utilización de la palabra «comunidad» véase: RuIz, Damien: «La Communaute' de l'Ordre et la papaute'd'Avignon», Cultura, arte e committenza nella Basilica di S. Antonio di Padova nel Trecento. Atti el Convegno internazionale di studi. Padova 24-26 maggio 2001, Padova, Centro di Studi Antoniani, 2003, pp. 117-136.

6. La temática en términos macros fue estudiada en diversos artículos de la autora y en una investigación de doctorado en donde se abordaron la conflictividad y la violencia en la orden franciscana como factor explicativo de diversos procesos histórico-coyunturales para todo el siglo XIII e inicios del XIV.

7. MARIN, Louis: «Poder, representación, imagen», Prismas, 13, 2009, pp. 136-7.

8. ChARTIER, Roger: Escribir las practicas. Foucault, de Certau, Marin. Buenos Aires, Manantial, 1996; Id., El mundo como representación. Estudios sobre historia cultural. Barcelona, Gedisa, 2005.

9. Ginzburg, Carlo: Rapporti di forza. Storia, retorica, prova. Milano, Feltrinelli, 2014.

10. Sobre su trayectoria más temprana véase: MonTEFusco, Antonio: «Autoritratto del dissidente da giovane. Gli anni della formazione di Ubertino nel primo Prologo dell'Arbor vitae», Ubertino da Casale. Atti del XLI Convegno internazionale di Studi Francescani e del Centro interuniversitario di studi francescani Assisi 18-20 ottobre 2013, Spoleto, Centro italiano di studi sull'Alto Medioevo, 2014, pp. 27-81. 
inclinó favorablemente hacia el pensamiento del fraile provenzal a tal punto que compuso un opúsculo para defender su doctrina: Sanctitati apostolicae. En I289 fue enviado nuevamente a París para continuar sus estudios y allí habría caído en una profunda crisis espiritual. Diez años después, volvió a Italia para ejercer su lectorado en Florencia y en I302/4 lo abandonó para desempeñarse como predicador itinerante en la Toscana, en el valle de Spoleto y en la Marca de Ancona.

Sabemos que probablemente se desempeñó como inquisidor y que, en $\mathrm{I} 305$, en el monte Alverna, comenzó a elaborar la primera versión de su obra más famosa: el Arbor vitae crucifixae lesu Christi ${ }^{\text {II }}$. A mediados de I306, dejó el monte Alverna luego de ser nombrado capellán del cardenal Napoleón Orsini con quien permaneció hasta $1325^{12}$.

Para 1309 Ubertino viajó a la corte de Aviñón con el objetivo de asistir al gran debate impulsado por Clemente $\mathrm{V}^{\mathrm{r}}$. Dicha reunión devino en Magna disceptatio y se extendió hasta el cierre del Concilio de Vienne en $\mathrm{I}_{3} \mathrm{I}^{\mathrm{I}}{ }^{4}$. Un poco antes del inicio del mencionado concilio, llegó a Aviñón fray Angelo Clareno con quien Ubertino se reunió ${ }^{15}$. En I3I7, fue convocado por el papa y luego de una serie de debates, el primero de octubre de I3I7, Juan XXII confeccionó la bula Verbum attendentes en donde estableció el traspaso de Ubertino a la Orden Benedictina. Sufrió varios procesos inquisitoriales hasta que finalmente, luego de ser nuevamente acusado de herejía, el pontífice lanzó un pedido de captura -vivo o muerto-, con la bula Cum Ubertinus en I325. El casalense huyó y se refugió bajo la protección de Orsini en Gembloux donde probablemente permaneció hasta su fallecimiento, aunque no se tienen certezas sobre la datación y el lugar del mismo ${ }^{\mathrm{i}}$.

La notoriedad de Ubertino dentro de la historia franciscana es peculiar ya que, si bien fue un sujeto muy conocido por las características que se le atribuyeron a su personalidad polémica -de las cuales, al menos en parte, probablemente se hallaba dotado-, esto conllevó a que durante bastante tiempo gozara de una fama estereotipada ${ }^{\mathrm{I} 7}$.

\footnotetext{
11. Sobre este texto también: PotestÀ, Gian Luca: Storia ed escatología in Ubertino da Casale. Milano, Vita e Pensiero, 1980.

12. VIAN, Paolo: «'Noster familiaris solicitus et discretus'. Napoleone Orsini e Ubertino da Casale», Ubertino da Casale. Atti del XLI Convegno internazionale di Studi Francescani e del Centro interuniversitario di studi francescani Assisi 18-20 ottobre 2013, Spoleto, Centro italiano di studi sull'Alto Medioevo, 2014, pp. 217-298.

13. Gratien de París: Op. Cit.

14. Martínez Ruiz, Carlos: «Historia y proceso redaccional del Arbor vitae», Ubertino da Casale. Atti del XLI Convegno internazionale di Studi Francescani e del Centro interuniversitario di studi francescani Assisi 18-20 ottobre 2013, Spoleto, Centro italiano di studi sull'Alto Medioevo, 2014, p. 121.

15. Sobre los dos personajes véase: VIAN, Paolo, «Angelo Clareno e ubertino da Casale: due itinerari a confronto», Angelo Clareno Francescano. Atti del XXXIV Convegno della Società internazionale di Studi Francescani e del Centro interuniversitario di studi francescani Assisi 5-7 ottobre 2006, Spoleto, Centro italiano di studi sull'Alto Medioevo, 2007, pp. 167-225.

16. CADILI, Alberto: «L'enigma degli ultimi anni di Ubertino da Casale», Ubertino da Casale. Atti del XLI Convegno internazionale di Studi Francescani e del Centro interuniversitario di studi francescani Assisi 18-20 ottobre 2013, Spoleto, Centro italiano di studi sull'Alto Medioevo, 2014, pp. 325-402. El autor sostiene que la muerte debería haber ocurrido entre 1325 y 1328 , año en el cual las menciones de Ubertino desaparecen.

17. BARTOLI, Marco: «Ubertino nella storiografia e oltre», Ubertino da Casale. Atti del XLI Convegno internazionale di Studi Francescani e del Centro interuniversitario di studi francescani Assisi 18-20 ottobre 2013, Spoleto, Centro italiano
} 


\section{LOS OPÚSCULOS DE UBERTINO}

Los debates entre las partes comenzaron en octubre de 1309 y frente a la tensión que se vivía entre los frailes, en abril de IзIo, Clemente $\mathrm{V}$ emanó la bula Dudum ad apostolatus, que significaba, de alguna forma, una victoria para los espirituales, ya que ponía freno a la comunidad y establecía que los frailes espirituales se encontraban bajo la protección de cardenales designados por el Sumo Pontífice por temor a los peligros. Así, se inaugura un período de enfrentamientos de diversas índoles en la Orden de los Menores ${ }^{18}$. Esta disposición, además, se llevó a cabo de cara al capítulo general que se realizaría en Padua un tiempo después. A partir de allí, se incrementaron los debates en donde se expresaron las posiciones de cada uno de los grupos. La situación de disputa extrema se expresa en las diferentes denuncias respecto a los posibles envenenamientos de diversos sujetos defensores de los rigoristas, como es el caso del propio Raimundo Gaufridi ${ }^{19}$. Las mencionadas circunstancias habrían sido tan polémicas que el mismo Ubertino, en su último opúsculo, sostiene que «por pudor las mantenían en secreto $»^{20}$.

Los debates entre las dos ramas de la Orden podrían periodizarse en dos etapas: una, en donde el grupo de los llamados espirituales habrían llevado la delantera favorable (fines de I3IO o inicios de I3II) que se dieron en Malaucene y luego en Aviñón; otra, en donde la comunidad retoma su impulso desde la segunda mitad de I3II y que comienza en Aviñón y termina en Vienne ${ }^{21}$. En esta etapa se sumarán tres teólogos a la comisión cardenalicia: Gerardo de Bologna, carmelita; Guillermo Peyre Godin, dominico y Arnaldo, agustino. La finalización de los debates se dilatará hasta el concilio de Vienne, convocado en octubre de I3II. Cuando en mayo de I3I2 concluyó dicho concilio, Clemente promulgó la bula Exivi de paradiso en donde se puso un punto -aunque no final- al debate entre las ramas de la Orden.

De los primeros meses de izio llegó a nuestros días el opúsculo denominado Sanctitas vestra ${ }^{22}$, en donde Ubertino desarrolla los puntos planteados con anterioridad por parte del ya entonces fallecido ex ministro general, fray

di studi sull'Alto Medioevo, 2014, pp. 3-26. Interesante es también la imagen inmortalizada de Ubertino en El nombre de la Rosa de Umberto Eco, en donde se lo presenta como un anciano perseguido por sus opositores.

18. La tensión entre los bandos y la problemática que enfrentaban los hermanos que se hallaban en los debates y que residían con sus frailes opositores, se materializa en un pedido anterior a la mencionada bula en donde el ex ministro general Raimundo Guafridi solicita al papa colocar a los frailes «espirituales» bajo la jurisdicción de los cardenales presentes. Véase «Répertoire de Raimundo de Fronsac», ALKG, III, 1887, p. 19: «...In quinto capitulo ponuntur petitiones, quas fecerunt domino pape frater Raymundus Gaufridi et eius socii contra ordinis bonum satatum...».

19. Raimundo Gaufridi según los testimonios de Angelo Clareno y Ubertino de Casale habría sido envenenado. Liber Chronicarum, VI, 122-3. Sobre el caso del ministro general véase PÉANO, Pierre: «Raymond Geoffroi. Ministre général et defenseur des Spirituels», Piacenum Seraphicum, XI, 1974, pp. 190-203.

20. «...quod eorum parcentes pudori eas in silentio contegamus...», «Declaratio...» en $A L K G, I I I, 1887$, p. 184.

21. Gratien de París: Op. Cit., p. 398.

22. Publicado por Franz Ehrle en $A L K G$, III, 1887, pp. 51-89. De aquí en adelante: «Sanctitas vestra...» 
Raimundo Gaufridi² ${ }^{23}$ Allí nuestro autor se dirige al pontífice sobre diversos elementos en conflicto y reconstruye la historia de la Orden desde su fundación, que él considera pura, hasta su decadencia.

Entre izıо у I3II se da la segunda fase del debate, allí fray Ubertino de Casale compone el posteriormente llamado Rotulus iste ${ }^{24}$ en donde denuncia veinticinco transgresiones que los frailes de la comunidad llevaban a cabo contra los preceptos de la Regla de san Francisco. Dicho escrito fue publicado -al igual que el anterior- por Franziskus Ehrle y editado en diálogo con las respuestas que efectuaron los frailes de la comunidad a las diversas acusaciones realizadas por Ubertino ${ }^{25}$. En términos de datación, se puede establecer el post quem de la obra: la misma habría sido posterior a la bula Dudum ad apostolatus de Clemente $\mathrm{V}$ (abril de I3IO), es decir, probablemente confeccionada a fines de I3Io o inicios de $\mathrm{I}_{3} \mathrm{II}^{26}$. En este texto, el fraile examina la situación de la Orden, enlistando los capítulos de la Regla y denunciando las infracciones realizadas por los frailes de la comunidad ${ }^{27}$. Posteriormente a su aparición, éstos últimos se presentaron ante el pontífice y requirieron revocar los privilegios que se habían otorgado a los frailes rigoristas con anterioridad.

Entre marzo y julio de I3II Ubertino redacta el texto Sanctitati apostolicae ${ }^{28}$, una apología en defensa de las doctrinas de fray Pedro Olivi, para evitar una condena de las posturas del fraile provenzal. En un texto extenso y complejo, Ubertino despliega todos sus recursos teóricos con el objetivo de demostrar al pontífice que las doctrinas del mencionado fraile -como los hermanos espirituales que las defendían- estaban siendo atacadas injustamente por la comunidad. Para alcanzar su meta, Ubertino recurre a los textos del mismo Olivi, como a Donus Scoto y Ricardo de Conington.

En efecto, su defensa será efectiva ya que, luego, Clemente V condenará como no ortodoxas solamente cuatro de las diez acusaciones que se realizaban sobre las doctrinas de $\mathrm{Olivi}^{29}$. A pesar de que es un escrito destinado a la defensa del

23. Probablemente anterior a este la comunidad presentó el texto conocido como Circa materiam de usu paupere en donde despliega su postura respecto al uso «moderado».

24. La edición del Rotulus iste se halla en ALKG, III, 1887, pp. 93-137. A partir de aquí: «Rotulus iste...».

25. Las repuestas de la comunidad son conocidas como Sapientia hedificavit. Para un análisis de los principales puntos de conflicto en las obras de Ubertino véase: LAMBERTINI, Roberto: «Ubertino contro la comunità», Op.Cit.

26. Para Roberto Lambertini, el Sapientia hedificavit es posterior al Rotulus iste, mientras que para Carlos Martínez Ruiz al revés. Véase: LAMBERTINI, Roberto: ibidem, p. 303; MARTínEz RuIz, Carlos: De la dramatización de los acontecimientos de la Pascua a la cristología. El cuarto libro del Arbor vitae crucifixae iesu de Ubertino de Casale. Roma, Pontificium Athenaeum Antonianum, 2000, p. 260.

27. Las faltas que denuncia Ubertino son: Distribución de los bienes de novicios entre los frailes, abundancia, riqueza y amplitud de los vestidos, utilización de calzado, viajes a caballo, recepción de pecunia, rentas, posesión de graneros, nombramientos y destituciones arbitrarias de ministros provinciales, grandeza de conventos, huertas, exceso en los estudios, entre los principales.

28. El texto fue publicado en ALKG, II, 1886, pp. 377-416. A partir de aquí: "Sanctitati apostolicae...».

29. En el decreto Fidei catholicae fundamento el pontífice decide no mencionar directamente a Olivi pero condena cuatro de sus doctrinas: las relativas a la esencia divina, el bautismo de los niños, la relación metafísica entre el alma y el cuerpo, y por fin, el pecho de Cristo atravesado por la lanza antes y no después de la muerte. 
fraile encontramos en ella varias situaciones denunciadas por Ubertino que podríamos caracterizar como violentas o de conflictividad extrema.

Asimismo, en esos tiempos Ubertino redactó el tratado Super tribus sceleribus en donde expone la teoría espiritual del uso pobre ${ }^{30}$.

La respuesta de la comunidad no se hizo esperar y tomó forma en un escrito dedicado con exclusividad a criticar la figura de Ubertino, sin detenerse en las cuestiones doctrinales $^{31}$. Por esto, y como último intento, en el mes de agosto de I3II, ya sobre el final del debate, Ubertino redacta la Declaratio fratris Ubertini ${ }^{32}$. Aquí vuelve a desplegar todos los argumentos y puntos conflictivos entre las dos ramas de la Orden y señala algunas situaciones en donde la transgresión de los frailes de la comunidad condujo a escenarios violentos. En este escrito, nuestro autor, intenta dar respuesta a las críticas dirigidas a su persona y demostrar que la Orden no vivía perfectamente en la pobreza querida por Francisco como habría sostenido la comunidad. Muchos de los debates entre los frailes devinieron en ataques sobre las personas y no en discusiones sobre las ideas de los actores. En los diálogos con la comunidad se evidencia esta tirantez constantemente ${ }^{33}$.

Los textos de Ubertino tienen una estructura discursiva que establece un diálogo constante con lo argumentado por sus hermanos opositores, son un planteo y una refutación de su parte en relación a diferentes tópicos. Estos textos tienen una naturaleza propia de opúsculos breves y concretos, confeccionados para ser presentados ante la comisión cardenalicia. Esto conlleva a que la esencia de los mismos no tenga una retórica literaria sino que los trabajos se caracterizan por una marcada especificidad discursiva.

A pesar de esto, el autor acude a una serie de recursos linguísticos concretos para referir a aquellas situaciones de adversidad extrema. Dichas referencias no son de carácter central en la obra de Ubertino, sino una herramienta para justificar el posicionamiento del grupo que representa, a la vez que argumentar las críticas realizadas a la otra rama de la Orden. El hecho de que no sea la intención principal del fraile hacer referencia a dichas cuestiones, dota de más riqueza e importancia el testimonio histórico del mismo.

En las próximas páginas, nos centraremos en indagar dichas situaciones que emergen de los textos en el marco del debate que lleva a la delantera Ubertino. Dentro de cada tópica desplegaremos las situaciones siguiendo el orden cronológico de los opúsculos. Una tópica es un sistema de recolección, producción y tratamiento de una información específica con diversas finalidades, que pueden ser narrativas, descriptivas, argumentativas, entre otras. Los topoi

30. Si bien fue trabajado, por sus características de tratado sobre la espiritualidad y no de denuncia será dejado de lado en este trabajo. Fue editado en AFH, X, 1917, pp. 103-174. AFH: Archivium Franciscanum Historicum.

31. Escrito conocido como Religiosi viri publicado en CHIAPPINI, Anicetus: «Communitatis responsio», AFH, 6, 1913, pp. 56-80 y su continuación en $A F H, 7,1914$, pp. 654-675.

32. Publicado en $A L K G$, III, 1887, pp. 162-195. A partir de aquí «Declaratio...».

33. Véanse por ejemplo las acusaciones que realizan los frailes de la comunidad a Ubertino en Religiosi viri. 
siempre funcionan en un contexto en el cual las representaciones y normas son, de alguna manera, homogéneas ${ }^{34} \mathrm{y}$ expresan una ontología popular específica. Estos recursos permiten al autor poner en evidencia las prácticas violentas y representarlas con alto grado de dramatismo potenciando, de esta forma, su mensaje. Los topos de conflictividad que emergen y que se reiteran en la obra del casalense son los siguientes: los encarcelamientos, los malos tratos y excesos, las difamaciones entre hermanos, los asesinatos y las persecuciones.

\section{LOS TOPOI ADVERSATIVOS EN LA OBRA DE UBERTINO DE CASALE}

\section{IV.I. ENCARCELAMIENTOS}

Las situaciones de encarcelamiento que narra Ubertino no solo muestran una práctica eclesiástica legal y utilizada como punición de manera habitual, sino también que son un recurso narrativo que el autor explota para poder referenciar situaciones que se hallaban fuera de lo normal, en relación a los tratamientos de los encarcelados o respecto a la injusticia de dichos aprisionamientos. La cárcel para él significa injusticia -ya que las razones por las cuales son encerrados dichos frailes son falsas-y se constituye como una ofensa -porque las condiciones son siempre descriptas como inhumanas como veremos más adelante-.

La referencia a los aprisionamientos es reiterada durante los debates y se constituye como una de las acusaciones más enérgicas que despliega el fraile defensor de los espirituales. Así, en el escrito denominado Sanctitas vestra, sostiene que aquellos que se declaraban en contra del estado de la Orden y que deseaban su reforma ab eis reputantur quasi heretici et ordinis destructores ${ }^{35}$; y por eso, muchos buenos hombres, expresa Ubertino, fueron encarcelados y sufrieron muertes crueles por querer continuar con el verdadero legado de Francisco.

En Sanctitati apostolicae, vuelve a denunciar encarcelamientos indebidos cuando arguye que los frailes espirituales fueron acusados falazmente y encarcelados injustamente sin respetar a Dios y a la «modestia humana» (humana verecundia) ${ }^{36}$. Ubertino utiliza este dispositivo retórico para señalar la complejidad de la situación que estaban viviendo en términos de conflicto. Busca extraer del campo de lo humano la acción para llevarla al espacio contrario con el objetivo de inhumanizar

34. Charaudeau, Pierre y Maingueneau, Dominique: Diccionario de análisis del discurso. Madrid: Amorrotu, 2005 , p. 558 .

35. Sanctitas vestra, p. 68,82 .

36. «... crimina falsa eis imponere et ubi possunt et incarcerare et aliis penis affligere, humana verecundia et dei timore postposito non verentur...», Sanctitati apostolicae, p. 381. 
a los perpetradores y dejar en claro la inocencia de los frailes que padecieron las persecuciones. La idea de que aquellos tratos eran contrarios al sentido de lo humano potencia en su mensaje lo inusual y terrible de la situación que estaban viviendo. Así, el casalense pone nombre a los frailes que fueron acusados, encarcelados y sometidos a muchas penas: fray Berengario de Campria, fray Ponzio Botugato, fray Raimundo Aurioli y fray Ubertino de Ripariolo ${ }^{37}$.

Continuando con la misma línea, en la Declaratio, Ubertino dedica gran cantidad de palabras a la situación vivida por los frailes de la provincia de la Marca de Ancona y Provenza. En la primera sostiene el casalense, los frailes rigoristas por no querer confesar que la comunidad recibía pecunia y otros bienes materiales en plena observancia de la Regla, sufrieron muchas penurias y fueron sentenciados como herejes a la cárcel perpetua ${ }^{38}$.

\section{EXCESOS Y MALOS TRATOS}

Las denuncias por tratos excesivos e injustos son un elemento importante dentro del despliegue de argumentos de Ubertino. Los castigos excesivos tienen que ver con los tratos pero también, como dijimos, con la aplicación de una pena considerada injusta. En el Rotulus iste el autor denuncia el accionar de los frailes de la comunidad en este sentido. Esto es a propósito del capítulo X de la Regla que establece que quienes no puedan observarla deben presentarse ante sus ministros, los cuales los deben acoger caritativamente. Según Ubertino, este aspecto de la Regla tampoco se respetaba y describe cómo dos frailes de la provincia de Provenza se presentaron ante el ministro provincial por las ilegales puniciones que recibían los frailes rigoristas y que, en vez de ser escuchados, su ministro los habría tratado despreciablemente y expulsado de la Orden ${ }^{39}$.

Asimismo, en Sanctitati apostolicae, como ya es habitual en el debate, cuestiona cómo aquellos que eran los verdaderos discípulos de Francisco y que querían seguir su mensaje en las provincias de centro-norte de Italia y sur de Francia fueron tiranizados con mucho dolor y maldad (cum multo dolo et malitia tyrannizant ${ }^{40}$ ); haciendo sufrir a los inocentes. El casalense también denuncia cómo muchos frailes de la comunidad decidieron tergiversar las palabras de Clemente $\mathrm{V}$ en la bula Dudum ad apostolatus y sostuvieron que los hermanos rigoristas no debían

37. «...quam fecit frater Berengarius de Campria et frater Pontius Botugati bone memorie et frater Raymundus Aurioli et multi de provintia ista et frater Ubertinus de Ripariolo in provincia Tuscie et plures alii in diversis mundi partibus appellaverunt ab iniquis iuditiis ipsorum, qui ex hoc in carceribus sunt positi...», Ibidem, p. 384.

38. «...Nam in provintia Marchie compulsi sunt fratres iurare, et qui noluerunt propter conscientiam nephandi periurii, sententiati sunt tanquam heretici perpetuo carceri in abstinentia dura...», Declaratio, p. 183.

39. «...patuit hoc in provincia Provincie in duobus fratribus, qui ex hoc, quod accesserunt ad ministrum pro predicto aeticulo viliter tractati sunt per suum ministrum scilicet fratre Petro Aychi et fratre Petro Raymundi de Falgueriis qui fuerunt sententiati, quod de ordine expellerentur...», Rotulus iste, p. 126

40. Sanctitati apostolicae, p. 380 . 
ser protegidos y que no valía dicho resguardo. De esta manera, Ubertino apelaba frente al Sumo Pontífice para poner en evidencia esta desprotección que podría llevar a situaciones de coerción extrema sobre los frailes de su grupo ${ }^{4 \mathrm{I}}$.

En el mismo texto, Ubertino señala que debido a la problemática del usus pauper muchos hermanos habrían sido perseguidos y encerrados en lugares casi mortales

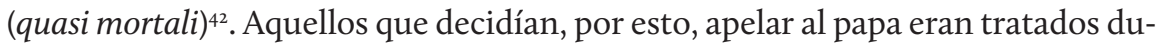
rísimamente hasta que retiraban la apelación; porque eran obedientes al ministro general pero desobedientes al pontífice ${ }^{43}$. Llega a denunciar, incluso, que los frailes que eran retenidos en sus celdas, eran atados con las cadenas entre su propia fetidez ${ }^{44}$; algo que igualmente fue manifestado por fray Angelo Clareno en el Liber Chronicarum cuando describe los padecimientos de fray Ponzio de Botugato ${ }^{45}$.

Algunos de estos frailes, sostiene el casalense, fueron enviados a la provincia de Aragón y allí sometidos a durísimos encierros, con fuertes cadenas y pasando hambre. En efecto, por causa de esto habría muerto un tal fray Raimundo, al igual que fray Juan, que fue liberado luego de la muerte de su compañero de celda y que logró escapar con dificultades ${ }^{46}$.

En la Declaratio, el fraile defensor de los espirituales, entre las diferentes referencias a las infracciones de la comunidad en relación a la pobreza y al usus pauper, sostiene que en la provincia de la Marca de Ancona y también en otras mandaban a quemar el testamento de Francisco. La situación de disputa en torno al controversial documento habría llegado a niveles insospechados e introduce una noticia singular: aparentemente, a un tal fray «N. de Rocanoto», quien es presentado como un hombre santo y devoto, los frailes de la comunidad le habrían quemado el testamento del santo de Asís sobre su mismísima cabeza: «...combuxerunt dictum testamentum super caput suum...»47. El hecho narrado por Ubertino en el contexto de la magna disceptatio nos refiere a una situación de conflictividad extrema inter frailes que devino en una escena de estas características. Sin dudas, la violencia física y simbólica del hecho es significativa, la brutalidad de lo descrito refiere

41. Ibidem, p. 383 .

42. «...voluit ad sedem apostolicam appellare, ex hoc carceri durissimo et quasi mortali traditus nunquam liberari potuit, donec omnino remedium provisionis romani pontificis respuit, renuntiando appellationi...», Ibidem, p. 381.

43. «...ac si maior sit obedientia domini generalis quam domini pape...», Ibidem, 381.

44. «...et sub utriusque predictorum regimine multi fratres nolentes confiteri predictam sententiam, que est contra evangelicam paupertatem et regulam nostram et declarationem ipsius, fuerunt diversis penis criminalibus puniti et diu in carceribus macerati, et aliqui ex eis viri sanctitatis eximie sunt fame, carceribus, chatenis et compedibus ponderosis in suis fetoribus contra omnem caritatis humanitatem crudelissime interempti...», Ibidem, p. 386.

45. El caso de Ponzio de Botugato fue analizado en otros trabajos como el de AccroccA, Felice: Un ribelle tranquillo. Angelo Clareno e gli spirituali francescani fra Due e Trecento. Assisi, Porziuncola, 2009, pp. 47-63.

46. «...Ex hoc fuerunt missi ad provintiam Aragonie et ibi durissimo carceri er gravibus catenis et compedibus mancipati et tam diu fame crutiati, quod dictus frater Raymundus ibi fuit modis predictis crudelissime interemptus, et frater Johannes extractus post mortem alterius, semimortuus vix evasit; et ex hoc predicti duo mortui privati ecclesiastica sepultura...», Ibidem, p. 386-7.

47. «...quod nephas est cogitare, in provintia Marchie et in pluribus aliis locis testamentum beati Francisci mandaverunt districte per obedientiam ab omnbibus auferi et comburi. Et uni fratri devoto et sancto, cuius nomen est N. de Rocanoto combuxerunt dictum testamentum super caput suum...», Declaratio..., pp. 168-9. 
a una controversia en torno a una identidad en disputa. No queda claro en el escrito el contexto en el cual este episodio se sitúa, de seguro habría que datarlo posteriormente a la bula Quo elongati de I230 en donde, el pontífice Gregorio IX había fijado el tenor legislativo del testamento.

Asimismo, Ubertino señala que a los frailes de la Marca de Ancona que habrían sido encarcelados por no querer transgredir la Regla, se les habría prohibido la tenencia de libros, leyendas y breviarios ${ }^{48}$, al igual que el contacto con otros hermanos, la confesión y la sepultura eclesiástica. Aclara también el fraile, que si alguien se atrevía a denunciar estos tratos era castigado con una pena similar ${ }^{49}$. En el caso de la Provenza, Ubertino destaca que frailes como Raimundo Aurioli y Juan Primi habrían sido condenados por el ministro general por la misma razón y, cuando se negaron a aceptar que el voto de pobreza no incluía el uso pobre, fueron per manus Saracenorum fabrorum cruelmente encerrados en cárceles pequeñas y con duras cadenas, sufriendo hambre y tratados con crueldad ${ }^{50}$. Cabe hacer una mención aquí a la referencia a los sarracenos, que son presentados simbólicamente como el mal y lo antagónico a la fe cristiana. Este es un recurso que aparece en otros testimonios de la Orden, como es el caso de Angelo Clareno, quien también utiliza la metáfora para representar situaciones de extrema crueldad.

Nuestro autor, asimismo, señala que la situación de los encarcelamientos injustos y excesivamente rigurosos se habrían reiterado como una práctica habitual en las diferentes provincias de la Orden y que dichos excesos y violencias habrían sido comprobadas por el testimonio de fray Raimundo Gaufridi y fray Guido de Mirapice que se habían desempeñado como auditores de dichas situaciones y el pontífice podría comprobarlo ${ }^{51}$.

En la conclusión de la Declaratio, Ubertino señala que los hermanos espirituales habrían probado a los cardenales presentes en el debate, los diferentes testimonios que emergían en el escrito y que por el intento de resistir a las transgresiones de la Regla alrededor de trecientos frailes de diversas partes padecieron grandes

48. Respecto a la posesión de libros en las cárceles la legislación no es clara. Las constituciones generales no especifican este aspecto punitivo, no obstante lo cual en los estatutos provinciales podemos hallar algunas pistas que nos permiten hacernos una idea -aunque sea parcial-: por ejemplo, en la constitución de la provincia Romana de 1316, se establece que el consejo de discretos debe decidir si los frailes que están en la cárcel pueden poseer libros (Cap. VII, art. 5); por el contrario, la constitución umbra del mismo año, establece que todos los encarcelados deben ser privados de los libros y el hábito (cap. VII, art. 9). Véase: Ed. LITTLE, Andrew: «Constitutiones Provincia Romanae. Anni 1316», AFH, 18, 1925, pp. 356-373; Ed. CENCI, Cesare: «Constitutiones Provinciales Provinciae Umbriae. anni 1316», AFH, 56, 1963, pp. 12-39.

49. «... et prohibitum est, ne quis librum ad legendum nec breviarium ad dicendum offitium procuraret nec aliquis loqueretur eisdem sub excommunicationis pena, ipsemet, qui eis ministrabat, nec audiretur eorum confessio et mortui carerent ecclesiastica sepultura, et si quis hanc iniquam diceret fore sententiam, tanqueam ipsorum fautor simili sententia puniretur...», Ibidem, p. 183.

50. «...Ex hoc, nullo alio crimine reperto in eis nec etiam apparenter imposito, fuerunt crudeliter per manus Saracenorum fabrorum, quos fratres ad hoc vocaverunt, duris compedibus stricti et in arcto carcere clausi et fame et aliis crudelitatibus taliter tractati...», Ibidem, p. 183.

51. «...Multi alii fuerunt ineareerati et crudelissime traetati [...] et sicut etiam probatio est in promptu, ymo notoria, si dominus papa voluerit indagare...», Ibidem, p. 184. 
privaciones y sufrieron durísimas encarcelaciones, algunos de ellos siendo asesinados -dice Ubertino- en cárceles brutales: por el hambre, las cadenas, los gusanos y con sus cuerpos contaminados por sus propias heces ${ }^{52}$.

\section{V.I. DIFAMACIONES}

La difamación o infamación aparece constantemente en los opúsculos. Esta se constituye como un ataque simbólico y entraña un acto de violencia que implica una injuria, algo por demás valuado en el contexto medieval53. La difamación/ infamación está asociada a algo fuertemente negativo y se materializa en acusaciones consideradas - por el denunciante- falsas: v.g. pertenecer a un grupo herético o denuncias que impacten directamente en la identidad de los sujetos, como ser cismático o apóstata, situaciones que podían llevar efectivamente a un escenario de violencia concreta.

Ubertino denuncia, en la Sanctitas vestra, que los hermanos que querían resistir a la impureza en términos de pobreza eran considerados contrarios al honor de la Orden y perseguidos. Asimismo, según el fraile, si quisiesen negarse a obedecer porque aquello era contrario a la Regla y los estatutos de la congregación, entonces eran tildados de inobedientes y castigados gravemente ${ }^{54}$. Así, según Ubertino, todo aquel que veía la corrupción de la Regla era considerado «enemigo de la cruz de Cristo y destructor del Evangelio y de la Iglesia de Cristo», así como hereje y destructor de la Orden ${ }^{55}$. La acusación de cismáticos envolvía una relativa gravedad: desde la misma legislación compuesta por Francisco encontramos referencias a la problemática del cisma en la Orden. En el capítulo XI de la Regla no bulada, el poverello señalaba que los hermanos deben guardarse de calumniar a otros y de enfrentarse entre ellos. Algo que reaparece en la Regla bulada en el capítulo Ill. Asimismo, la constitución de Narbona de i26o establecía la pena de excomunión y apartamiento de la comunidad para los cismáticos hasta que cumplan la pena impuesta (Artículo I3, Narbona I260).

Por otro lado, Ubertino repite que cuando los frailes spirituales alegaban contra las transgresiones que veían eran llamados herejes y sectarios, por lo cual habrían

52. «...quod pro veritate regule servande et pauperis usus plus quam ccc fratres in diversis partius privaverunt libris, locis, custodiies et provintiis, actibus legitimis et offitiis ordinis et habitu et multus ex eis durissimis carceribus manciparunt et quosdam ex eis viros sanctissimos, quod dictu nephas est, in crudelibus carceribus fame, ferro et vermibus in propriis fecibus cruenti carnifices occiderunt...», Ibidem, p. 192.

53. Véase Muchembled, Robert: Una historia de la violencia. Del final de la Edad Media a la actualidad. Madrid, Paidós, 2010.

54. «...reputatur non amare honorem ordinis, immo quasi persecutor ordinis persecucionem recipit habundanter, et si diceret, quod nollet in hoc obedire, quia est contra nostram regulam et statuta, reputaretur inobediens et graviter puniretur...», Sanctitas vestra..., p. 55.

55. «....reputator ab eis inimicus crucis Christi et destructor evangelii et ecclesie Christi...»; «...Et, si sunt fratres, qui illuminati vident predictam infectionem regule et dicant, ista repugnare statui, ab eis reputantur quasi heretici et ordinis destructores...». Ibidem, pp. 81-82. 
sufrido juicios impíos como en la Toscana, Provenza y en la Marca de Ancona y en muchos otros lugares ${ }^{56}$.

El recurso y abuso de la ley por parte de los frailes de la comunidad aparece en repetidas ocasiones en el texto del nuestro autor, quien considera que el encasillamiento de los hermanos rigoristas como sectarios o herejes era injusta e inexplicable, ya que para él eran solo seguidores de la Regla y denunciantes de las infracciones de sus hermanos de la comunidad.

Al referirse a la situación de la vestimenta -otro elemento conflictivo entre los grupos- vuelve a asomar este recurso: aquellos que portaban el hábito riguroso, como el del mismísimo san Francisco, eran considerados sectarios y, por ello, castigados $^{57}$. Lo mismo sucedía con la comida o las celdas, factores de polémica dentro de la Orden. En efecto, según Ubertino, cuando los frailes querían seguir los principios de pobreza eran llamados supersticiosos y detractores de la Orden, perseguidos, criminalizados y arrastrados a los príncipes y prelados ${ }^{58}$.

En el Rotus iste resurge la problemática de la vestimenta: aquellos que querían proseguir con la vileza de los vestidos que se hallaba estipulada por san Francisco y que no querían llevar los hábitos largos y suntuosos, remarca Ubertino posteriormente, eran perseguidos y difamados y no podían tener paz entre sus propios hermanos (nec pacem) ${ }^{59}$. Asimismo, señala que no podían vivir todos juntos, porque los frailes de la comunidad perseguían a aquellos de manera horrenda y los infamaban mendazmente como destructores de la Orden ${ }^{60}$.

La problemática no está ausente tampoco en Sanctitati apostolicae: según Ubertino los frailes de la comunidad se habrían esforzado en oprimir, infamar, acusar y castigar por crímenes falsos a los hermanos del centro-norte de Italia y sur de Francia que querían seguir los preceptos del padre fundador ${ }^{61}$.

Como se dijo, este texto fue confeccionado con el objetivo de defender la figura de Olivi frente al pontífice. Al referirse a las persecuciones que tuvo que sufrir el

56. «...vocant eos hereticos aliqui stulti prelati et facientes sectam, sicut patet in impiis iudiciis factis super eos in provincia Tuscie et provincia Provincie et provincia Marchie et in aliis locis multis...», Ibidem, p. 56. Las presiones e injurias sufridas por los frailes de la provincia de la Toscana y Provenza son repetidas por Ubertino en las conclusiones del texto: «...iniustis gravaminibus notabilibus fratrum, satis dictum est de iudiciis provincie Provincie et Tuscie, et ex superioribus multa patent...», Ibidem, p. 88. Sobre la situación de los frailes de la Toscana véase: INI, Anna Maria: «Nuovi documenti sugli spirituali di Toscana», AFH, 66, 1973, pp. 305-377.

57. «...et qui volunt tunicas habere et repeciatas et unam solam inferius portare et ire sine soleis, sicut ibant prim patres nostri et beatus Franciscus, de quo numquam dicitur, quod soleas habuerit, reputantur superticiosi et facientes sectas et persecutionem recipiunt ab aliis et despectum...», Ibidem, p. 57.

58. «...in vestibus sive in cibis seive in cellis volentes se paupertati fratrum et regule conformare vocant singulares et supersticiosos et ordinis detractores. [...] hii fratres relaxati persecuntur et criminantur et eis detrahunt aput principes nobiles et prelatos...», Ibidem, p. 66.

59. «...Quod si nolunt, multas persecutiones eis faciunt er eos diffamant et reputant singulares, nec pacem possunt tales viri spirituales inter fratres habere...», Rotulus iste, p. 102.

6o. «...non possunt pacifice vivere inter eos, quia eos horrendis modis et dolosis fallaciis persequuntur et infamant eos mendaciter et vocant ordinis destructores, per quis videntur defectus suprascriptos ordinem nominare...», Ibidem, p. 119.

61. «...et ab hiis quasi omnia scandala et infamie ordinis oriuntur et communitas fratrum pauperum et innocentum gemit sub eis, sicut multi boni fratres et valentes et integre fame de diversis provintiis...»y «...nituntur tales opprimere, infamare et infames reddere...», Sanctitatis apostolicae, p. 381. 
fraile provenzal, Ubertino señala que los hermanos de la comunidad hablaron sobre él de manera mendaz e impía y que la bestialidad de estos lo devoró ferozmente «con muchos mordiscos» ${ }^{62}$; así, su sangre y la de otros innocentium fratrum habría sido derramada. A nivel lingüístico, aquí, el fraile espiritual introduce la metáfora de los mordiscos para representar con un pathos dramático la situación vivida por Olivi. Aparece aquí el recurso habitual de la situación de caza y de lo «bestial» para representar un escenario de violencia extrema. Con esta hipérbole lo que pretende el autor es remarcar lo trágico de la situación denunciada. Así, las características atribuidas a las bestias feroces -como lo inhumano o la crueldad-se vuelcan sobre los sujetos perpetradores ${ }^{63}$. Lo animal funciona como metáfora de todo aquello que escapa al entendimiento de los protagonistas, utiliza el recurso de la animalidad para representar situaciones que se salen de lo «común» o «esperable».

Recurre a esto sosteniendo que nadie que conociera la noticia podría negarla o dudar de ella, intentando por este medio persuadir al Sumo Pontífice de la gravedad de las persecuciones padecidas en el pasado y haciendo referencia a los peligros del presente.

\section{V.II. LAS MUERTES}

Las muertes y asesinatos son la expresión más básica y evidente de violencia. La legislación interna de la Orden, es decir, las constituciones generales introducen regulaciones a situaciones que son de por sí explícitas que hablan de un contexto de violencia: como la prohibición y castigo de mutilar, asesinar o golpear hermanos con espadas o piedras ${ }^{64}$. De igual manera, los asesinatos se encuentran recurrentemente presentes en los escritos del fraile. En Sanctitas vestra luego de denunciar los encarcelamientos injustos, el fraile señala que muchos de los hermanos apresados sufrieron muertes crueles ${ }^{65}$ como consecuencia de dichos aprisionamientos y señala además que aquellos fallecimientos se hallaban probados.

En el opúsculo denominado Sanctitati apostolicae en donde Ubertino denuncia el encarcelamiento injusto de varios frailes que él consideraba inocentes -como fray Berengario de Campria, fray Ponzio Botugato, fray Raimundo Aurioli y fray

62. «...ipsos mendaciter et impie loqui in fratrem suum uterinum, quem in medio ipsorum sancte conversatum detractionis et invidie ipsorum ferina bestialitas morsu multiplici devoravit. Cuius sanguis et aliorum innocentium fratrum, quos pro zelo sue observande regule et voluntate perverse loquendi, sicut ipsi precipiebant eis et nunc publice dogmatizant, quod nullus abusus rerum frangit substantiam voti evangelize paupertatis, exquirunt in scandala, que a secularibus ubilibet prohdolor patiuntur...», Ibidem, pp. 406-7.

63. Véase la fórmula cinética de capítulo Il en BuRucúA, José y KwIATKOWSkY, Nicolás, Cómo sucedieron las cosas. Representar masacres y genocidios. Buenos Aires, Katz, 2014.

64. Esto aparece en diferentes constituciones pero principalmente en las de Padova de 1310 y de Lyon de 1325. La regulación legislativa de conflictos fue abordada en otros trabajos.

65. «... et per hoc plures boni fratres timentes, se negare evangelium, si separarent a paupertate evangelica pauperem usum, quia hoc noluerunt negare, carceres pertulerunt et mortes crudeles, sicut plures offerunt se probaturos...»., Sanctitas vestra, p. 82 . 
Ubertino de Ripariolo -introduce la noticia de que varios de ellos tras soportar muchas penas, fueron asesinados (interempti). El caso de fray Ponzio -al igual que Raimundo Aurioli y Juan de Primi- es mencionado como el primer ejemplo de los abusos de los frailes de la comunidad ${ }^{66}$. En este sentido, existe una marcada coincidencia con el testimonio de Angelo Clareno en la crónica y en sus otros textos respecto a su muerte. Ya sobre el final del texto, Ubertino vuelve a hacer referencia a Ponzio, al acusar que muchos frailes al intentar acercarse al pontífice para explicar los libros que eran considerados heréticos de Pedro Olivi, sufrieron diversos maltratos y fueron asesinados: dichos hermanos habrían sufrido injustos encarcelamientos, crueles castigos y habrían sido asesinados cruelmente (crudeliter in carceribus occidebant); como es el caso del mencionado fraile y muchos otros ${ }^{67}$.

Los asesinatos se reiteran en el último escrito del defensor de los espirituales, la Declaratio. El casalense sostiene que fray Raimundo Aurioli fue asesinado cruelmente (crudeliter est oecisus) porque no quería retractarse y sostener que la pecunia era aceptable según la Regla, por esto habría sido tratado como un hereje, privado de los sacramentos y de la sepultura eclesiástica. Por otro lado, Juan de Primi habría sido recluido hasta su muerte evadiendo los castigos. Es también mencionado fray Ponzio de Botugato -igual que anteriormente- que habría sido asesinado por los frailes de la comunidad durante su encarcelamiento ${ }^{68}$.

Más allá de estos casos particulares, Ubertino denuncia que muchos habrían enfermado y muerto por dichos excesos: qualiter autem tractaverunt, testes sunt egritudines et mortes quam plurium ipsorum ${ }^{69}$.

\section{V.III. PERSECUCIONES}

La persecución es otro de los nudos de conflicto que Ubertino plantea frente a la comisión. Como consecuencia de que los frailes de la comunidad no se atenían a las disposiciones del pontífice amparándose en las difamaciones, el casalense denuncia que muchos hermanos fueron perseguidos atrociter $^{70}$ por querer continuar con el verdadero legado de Francisco ${ }^{71}$. Además, sostiene que aquellos que denunciaban

66. «...et aliqui fame et aliis penis in eisdem carceribus interempti (sunt)...», Sanctitati apostolicae, p. 384 .

67. «...quia ipsi omnem fratrem qui volebat libros ad limam summi pontificis ducere, incarcerabant; immo, quod horrible est dictu, crudeliter in carceribus occidebant, sicut patet in crudeli morte, quam propter hoc fecerunt magne sanctitatis et excellentis et punitis crudeliter et non obstantibus appellationibus ad apostolicam sedem factis...», Ibidem, p. 409.

68. «...quod frater Raymundus Aurioli ibi crudeliter est oecisus et, quia revocare noluit, tanquam hereticum eum privaverunt sacramentis et eclesiastica sepultura; et frater Johannes Primi usque ad mortem deduetus, vix eum penis evasit. Item frater Pontius Bautugati vir excellentissime sanctitatis in carcere Nemausi fuit ab eis crudelissime interemptus...», Ibidem, p. 184.

69. Idem.

70. Sanctitas vestra, p. 86 .

71. «...reputantur superticiosi et facientes sectas et persecutionem recipiunt ab aliis et despectum...», Ibidem, Ibidem, p. 57. 
los excesos en los edificios, que para el fraile se contradecían fuertemente con el ideal de pobreza propuesto por Francisco, eran perseguidos como «destructores de la orden» (ordinis destructores), sectarios y herejes y se les imponía penas graves. Dentro de los perseguidos, vuelve a revelar el fraile, se hallaban los hermanos de la provincia de Toscana ${ }^{72}$. Es dable señalar que, al inicio del texto, Ubertino exclama que una de las características de la perfección evangélica es la caridad perfecta «...y por eso huye de las persecuciones y de los odios mutuos...» ${ }^{73}$.

En las conclusiones del escrito, Ubertino sostiene que siempre existieron aquellos que eran celadores de la Regla de Francisco y «...siempre existirán quienes los persigan, de modo que nunca habrá paz...» ${ }^{74}$. Sobre el final, hace referencia a los padecimientos de los frailes rigoristas de Toscana y Provenza, ya que los superiores de la Orden (ex superioribus multa patent) les habrían impuesto injustas presiones (iniustis gravaminibus) 75 .

En el Rotulus iste, al comentar el capítulo Il de la Regla, Ubertino pone en evidencia el clima de conflictividad interna de la Orden: los hermanos rigoristas no podían llevar los hábitos según su visión o interpretación de la Regla sin ser perseguidos. En efecto, el fraile sostiene que la mayoría de los hermanos se relajaban respecto a las vestimentas y que solo unos pocos seguían los preceptos al pie de la letra, y por esto recibían reprimendas y persecuciones sobre sus personas ${ }^{76}$.

Al mencionar las transgresiones al capítulo VI de la Regla, que se refiere a la pobreza de los frailes, fray Ubertino denuncia cómo aquellos que se preocupaban por la Orden y se proclamaban en contra de los abusos a propósito de estos aspectos eran perseguidos como supersticiosos y gravemente castigados ${ }^{77}$. En la misma línea, continuando con el sexto capítulo, el casalense comenta que quienes querían vivir más relajadamente se unieron contra los frailes que vellent pro veritate regule zelare et predictis defectibus repugnare ${ }^{78}$.

Al detenerse en el contenido del apartado X de la Regla -que trata sobre la corrección y amonestación de los frailes- Ubertino acusa que muchas veces no eran justas las puniciones aplicadas a los hermanos, que se administraban incluso sobre aquellos que sólo querían observar la Regla. Este habría sido el caso de los

72. «...ipsi reputati sunt ordinis destructores et facientes sectas et nominati heretici et gravius penis puniti et aliqui incarcerati. [...] inter alia persecucio, quam fratres paupertatis amatores in Tuscia habuerunt, ut patet in actis...», Ibidem, p. 68.

73. «...in caritate perfecta, ac per hoc fugit mutuas persecuciones et odia...». Ibidem, p. 52.

74. «...Nam per dei graciam et merita beati Francisci zelatores regule semper fuerunt in isto ordine et erunt et eorum persecutores, et sic nunquam pax erit, maxime modo, quia nimis notabiliter est corrupta, et non est multitudo disposita ad relinquendum predicta, que causa sunt scandalorum... », Ibidem, pp. 87-88.

75. Ibidem, p. 88 .

76. «...et hi reprehensionem et persecutionem pluries patiuntur et singulares reputantur...», Rotulus iste, p. 100.

77. «...et qui contra ista clamant vel qui pro hiis congregandis ire nollent, tanquam superstitiosi persecutiones multas patiuntur et graviter puniuntur...», Ibidem, p. 115.

78. «...qui adinvicem sunt divisi et in relaxationibus predictis volunt vivere, sic uniuntur contra fratres, qui vellent pro veritate regule zelare et predictis defectibus repugnare, quod nisi remedium apponatur...», Ibidem, p. 119 . 
frailes de la Provenza, Toscana, Umbría, Marca de Ancona y otros lugares ${ }^{79}$. En efecto, el fraile denuncia cómo otros no fueron castigados debidamente, como la secta del «libre espíritu» que él mismo habría desmantelado ${ }^{80}$. En este caso nuestro autor explicita que el nivel de persecución personal que vivía la Orden se habría profundizado tanto que los ministros y prelados de aquellas mismas provincias habían sido por mucho tiempo (multa tempora) negligentes con una secta, que merecía ser castigada a los ojos de Ubertino. En algunos casos, sostiene el fraile, se impidieron las puniciones dignas y en otros, se las procuró falsamente ${ }^{8 \mathrm{r}}$.

En el cierre del opúsculo Sanctitati apostolicae, el casalense dirige directamente al pontífice una petición de uno o varios cardenales protectores porque consideraba que ni para él ni para su grupo «existía seguridad mientras que aquellos [los frailes de la comunidad] tuviesen potestad sobre ellos», ya que tiranizaban con malicia a los amatores regule ${ }^{82}$. El pedido a Clemente $\mathrm{V}$ es demostración de los niveles de coerción y violencia que se habrían instituido en la Orden a inicios del siglo XIV. Poniéndolo en otras palabras: Ubertino, un integrante de la Orden, solicitó al Sumo Pontífice protección externa ya que corría riesgo su vida y la de sus compañeros entre sus propios hermanos.

En relación a los excesos en la tenencia de libros o en la indumentaria, Ubertino vuelve a destacar en su Declaratio que muchos hermanos de diversas provincias fueron castigados (fuerunt punitus) porque no querían transgredir lo establecido en la Regla sobre estos asuntos ${ }^{8}$. Acusación que, según el fraile, nadie en toda la Orden podía desmentir, ya que muchos de ellos fueron cruelmente sancionados por causas mendaces. De hecho, los ministros y los prelados de la Orden, sostiene

79. «...Patet hoc in fratribus iniuste punitis pro materia et zelo paupertatis et observantia regule in provincia Provincie et in Provinciis Tuscie, sancti Francisci, Marchie et Janue et in aliis multis locis...», Ibidem, p. 123.

80. «... Patet etiam hoc per contrarium in illis vilissimis hereticis, qui reperti sunt in provincia sancti Francisci, circa quorum correctionem ministri et prelati alii fuerunt per multa tempora negligentes et ei, qui cum multo labore et periculo prudenter eos deprehendit et punivit, tales referunt grates, ut vos ipsi domini experimini, quia tales sibi persecutiones excitant et ipsum infamare impie non verentur...», «...quando tales dortiter impugnant et persequuntur fratres pauperculos zelantes pro regule puritate...», Ibidem, p. 123.

Este caso que trae a colación el fraile defensor de los espirituales se halla descripto en el Liber Chronicarum de Angelo Clareno.

81. «...Et sepe contingit, quod multorum deprehensio et digna punitio de criminibus impeditur, et aliorum confusio multum sollicite et astute et aliquando fallaciter et mendaciter procuratur...», Ibidem, p. 123.

82. «...Videte autem pater sanctissime, quanta necessitas est, quod nos et nobis adherentes efficaciter protegatis et executores protectionis date vel sande fatiatis poni in lictera unum aut plures dominos cardinales. Immo attendat apostolica pietas ex huius libelli malignitate et aliis multis signis odii contra nos et postpositionem conscientie ipsorum, ultrum aliqua protectio inter viros tales reddere nos possit securos, dum habuerint prelationis potestatem super nos et alios bonos fratres hii, quorum consilio ista et qui relaxationes nutriunt et multis molestiis in amatores regule tyranizant...», Sanctitati apostolicae, p. 415 .

83. «...Et plures ex eis puniti sunt, quia nolebant excessus transgressorios regule sequi, de quo exempla sunt plurima, quibus universis ordo respondere non poterit, in provintia Tuscie, Janue, sancti Francisci, Marchie et in provintia Provintie et in multis altri locis. Et licet in aliquibus mendaciter et in aliquibus dolose alias causas producant, tamen multi sunt ab eis crudeliter ex sanctitate et zelo et observantia regule puniti, contra quos non possunt fingere aliud criminale...», «Declaratio...», pp. 172-3. 
Ubertino, se esforzaban en «extinguir» (extinguere) a aquellos que querían evitar los relajamientos ${ }^{84}$.

\section{CONCLUSIONES}

Fray Ubertino de Casale en el marco del debate con la comunidad, en presencia del pontífice y de los cardenales, despliega una serie de acusaciones -en relación a las situaciones adversativas- que en general se ven atravesadas por una estructura común: los frailes de su grupo, quienes intentaron seguir los preceptos de la Regla y el Testamento respecto a la pobreza -vestidos, propiedades, etc.- se vieron ante la difícil situación de enfrentar las persecuciones violentas que encontraron en el marco de la legalidad el instrumento para apresarlos y coercionarlos. Dicho proceder se amparó, en muchos casos, en la figura de sectario o destructor de la orden, hereje o supersticioso para perseguir a los frailes que, según el casalense, eran inocentes. Así las situaciones como encarcelamientos, malos tratos, difamaciones, muertes y persecuciones se constituyen como reprobables a los ojos de Ubertino. Esto abarcaría desde lo que consideramos violencia física concreta (como los asesinatos) hasta la violencia que podríamos calificar de simbólica (como las difamaciones).

Para Ubertino los castigos fueron excesivos porque las condiciones a las que se sometía a los frailes eran inhumanas y de un fuerte tenor violento. Muchas de esas condiciones conllevaron a la pérdida física de los sujetos que las padecieron. La sucesión de los escritos permite deducir que los asesinatos no fueron desmentidos por los referentes de la comunidad. Por otro lado, el mantenimiento de las denuncias por parte del autor hasta su último escrito, Declaratio..., es prueba de que -al menos- estaba convencido de su veracidad. Es sugestivo en este sentido, como ya se ha señalado, la utilización que Ubertino realiza del vocabulario: es más técnico a la hora de expresarse en los opúsculos; y pone en manifiesto su conocimiento de la legislación interna.

El eje del debate aquí no tiene que ver con la actividad coercitiva per se sino con su aplicación injusta, es decir con el abuso de poder de aquellos que conducían la congregación. Ese uso/abuso de la fuerza se constituye como la expresión de una lógica más amplia de disputa por una identidad específica que era concebida de diversas maneras por cada grupo. En este sentido la discursiva en torno a lo verdadero y lo falso cobra una importancia significativa a propósito de las situaciones adversativas. Tal y como ha señalado el egiptólogo Jan Assmann para las religiones monoteístas, la taxonomización de la verdadera fe y la falsa conlleva

84. «...respondemus, quod ipsi, ut plurimum, sunt istorum auctores malorum et non punient conformes vite sue, sed nituntur omnes, qui volunt a suis relaxationibus deviare...», Ibidem, p. 173. 
una inclinación hacia la violencia. Esto se ve claramente expresado en la construcción dualística de los sujetos: para Ubertino, el grupo al que él representa son los verdaderos seguidores de la Regla de Francisco; mientras que los otros, eran aquellos que traicionaban su mensaje.

El tono de las noticias introducidas por Ubertino nos permite replantearnos el rol que tuvieron los hechos de violencia al momento de resolver los conflictos procedentes de los mismos intersticios de la Orden y que expresaban un profundo quiebre entre los sujetos involucrados respecto a la memoria de Francisco y la identidad minorítica. 


\section{BIBLIOGRAFÍA}

AFH - Archivium Franciscanum Historicum, Quaracchi- Gottaferrata.

ALKG - Archiv Für Literatur-und Kirchengeschichte des Mittelalters, Freiburg i. B.

AcсrосcA, Felice: Un ribelle tranquillo. Angelo Clareno e gli spirituali francescani fra Due e

Trecento. Assisi, Porziuncola, 2009.

Assmann, Jan: Violencia y monoteísmo. Barcelona, Fragmenta, 2014.

BARTOLI, Marco: «Ubertino nella storiografia e oltre», Ubertino da Casale. Atti del XLI Convegno internazionale di Studi Francescani e del Centro interuniversitario di studi francescani Assisi I8-20 ottobre 2013, Spoleto, Centro italiano di studi sull'Alto Medioevo, 20I4, pp. 3-26.

BURR, David: The spiritual franciscans: from protest to persecution in the century after saint Francis. Pennsylvania, The Pennsylvania State University Press, 200 I.

BurucúA, José y KwiAtKowsky, Nicolás, Cómo sucedieron las cosas. Representar masacres y genocidios. Buenos Aires, Katz, 2014.

CADILI, Alberto: «L'enigma degli ultimi anni di Ubertino da Casale», Ubertino da Casale. Atti del XLI Convegno internazionale di Studi Francescani e del Centro interuniversitario di studi francescani Assisi I8-20 ottobre 2013, Spoleto, Centro italiano di studi sull'Alto Medioevo, 2014, pp. 325-402.

CEncl, Cesare, «Constitutiones Provinciales Provinciae Umbriae. anni I3I6», AFH, 56, I963, pp. I2-39.

Charaudeau, Pierre y Maingueneau, Dominique: Diccionario de análisis del discurso. Madrid: Amorrotu, 2005.

ChARTIER, Roger: Escribir las practicas. Foucault, de Certau, Marin. Buenos Aires, Manantial, I996; ChARTIER, Roger: El mundo como representación. Estudios sobre historia cultural. Barcelona, Gedisa, 2005.

Chiappini, Anicetus: «Communitatis responsio», AFH, 6, I9I3, pp. 56-80 y su continuación en $A F H, 7$, I9I4, pp. 654-675.

Cusato, Michael: «Whence «The Community»?», Franciscan Studies, 2002, 6o, pp. 39-92.

Ginzburg, Carlo: Rapporti di forza. Storia, retorica, prova. Milano, Feltrinelli, 2014.

GRATIEN DE PARís: Historia de la fundación y evolución de la Orden de los frailes menores en el siglo XIII. Buenos Aires, Dedebec, I947 [I ed. I926]

INI, Anna Maria: «Nuovi documenti sugli spirituali di Toscana», AFH, 66, I973, pp. 305-377.

LAMBerTinI, Roberto: «Ubertino contro la comunità», Ubertino da Casali. Atti del XLI convegno internazionale d'Assisi, Società internazionale di studi francescani, Spoleto, 20I4, pp. 299-323.

LitTle, Andrew: «Constitutiones Provincia Romanae. Anni I3I6», AFH, I8, I925, pp. 356-373.

MARIN, Louis: «Poder, representación, imagen», Prismas, I3, 2009, pp. I35-I53.

MARTínez Ruiz, Carlos: «Historia y proceso redaccional del Arbor vitae», Ubertino da Casale. Atti del XLI Convegno internazionale di Studi Francescani e del Centro interuniversitario di studi francescani Assisi I8-20 ottobre 2013, Spoleto, Centro italiano di studi sull'Alto Medioevo, 20I4, pp. II3-I48.

Martínez Ruiz, Carlos: De la dramatización de los acontecimientos de la Pascua a la cristología. El cuarto libro del Arbor vitae crucifixae iesu de Ubertino de Casale. Roma, Pontificium Athenaeum Antonianum, 2000.

Merlo, Giovanni Grado: Nel nome di san Francesco. Padova, Editrici Francescane, 2012. 
Montefusco, Antonio: «Autoritratto del dissidente da giovane. Gli anni della formazione di Ubertino nel primo Prologo dell'Arbor vitae», Ubertino da Casale. Atti del XLI Convegno internazionale di Studi Francescani e del Centro interuniversitario di studi francescani Assisi I8-20 ottobre 20I3, Spoleto, Centro italiano di studi sull'Alto Medioevo, 20I4, pp. 27-8I.

Muchembled, Robert: Una historia de la violencia. Del final de la Edad Media a la actualidad. Madrid, Paidós, 20 Io.

PÉAno, Pierre: «Raymond Geoffroi. Ministre général et defenseur des Spirituels», Piacenum Seraphicum, XI, I974, pp. 190-203.

Potestà, Gian Luca: Storia ed escatología in Ubertino da Casale. Milano, Vita e Pensiero, 1980.

Ruiz, Damien: «La Communaute 'de l'Ordre et la papaute' d'Avignon», Cultura, arte e committenza nella Basilica di S. Antonio di Padova nel Trecento. Atti el Convegno internazionale di studi. Padova 24-26 maggio 200I, Padova, Centro di Studi Antoniani, 2003, pp. II7-I36.

VIAN, Paolo, «Angelo Clareno e ubertino da Casale: due itinerari a confronto», Angelo Clareno Francescano. Atti del XXXIV Convegno della Società internazionale di Studi Francescani e del Centro interuniversitario di studi francescani Assisi 5-7 ottobre 2006, Spoleto, Centro italiano di studi sull'Alto Medioevo, 2007, pp. 167-225.

Vian, Paolo: «'Noster familiaris solicitus et discretus'. Napoleone Orsini e Ubertino da Casale», Ubertino da Casale. Atti del XLI Convegno internazionale di Studi Francescani e del Centro interuniversitario di studi francescani Assisi I8-20 ottobre 20I3, Spoleto, Centro italiano di studi sull'Alto Medioevo, 20I4, pp. 217-298. 
Calidad de Revistas

Científicas Españolas

FECYT |
SERIE III HISTORIA MEDIEVAL

REVISTA DE LA FACULTAD DE GEOGRAFÍA E HISTORIA
AÑO 2020

ISSN: 0214-9745

E-ISSN 2340-1362

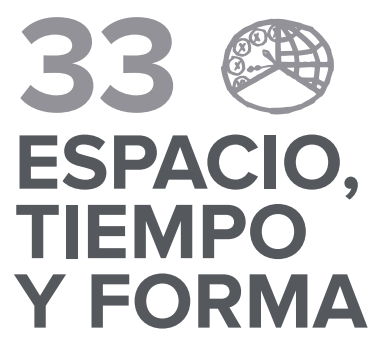

\section{Artículos · Articles}

7 FREDERIC APARISI ROMERO

El cultivo y procesado del lino en el Reino de Valencia (ss. XIII-XVII)

13 ADRIÁN CALONGE MIRANDA

El mantenimiento del entramado viario romano en época medieval en La Rioja. Algunos casos de estudio

\section{Miguel Calleja Puerta}

Notarios públicos entre dos reinos. Apuntes diplomáticos sobre documentos notariales castellanos en el Arquivo Distrital de Braga

\section{Xavier Casassas Canals}

Las 'aqida-s entre los musulmanes castellanos y aragoneses de época mudéjar y morisca: Las 'aqida-s de lbn Abi Zayd Al-Qayrawāni (s. X), Ibn Tümart (s. XII) e Isa de Jebir (s. XV)

\section{ARCADIO DEL CASTILLO}

Sobre el Códice Alcobacense de Vaseo y los Annales Portugalenses Veteres: Continuidad del reino visigodo de Toledo

\section{Paula Castillo}

Las formas de la violencia entre frailes. El testimonio de Fray Ubertino de Casale

\section{María Eugenia CONTRERAS JIMÉnEZ}

La memoria del linaje Arias Dávila en la cofradía y hospital de San Cosme y San Damián de Valladolid (siglos XV a XVII)

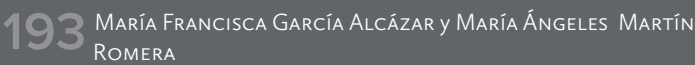
Entre servicio regio y estrategia personal: Los Continos de Valladolid (1480-1525)

\section{César García de Castro Valdés y josé Antonio Valdés
Gallego}

Las inscripciones perdidas de la basílica altomedieval de San Salvador de Oviedo

\section{María José Lop OtÍN}

Hay tal número de clérigos que causa asombro. La clerecía de Toledo a fines de la Edad Media

\section{CORINA LUCHÍA}

Por que los montes de esta villa se conserben, e no se disipen como al presente estan: La regulación de los recursos forestales en la Corona de Castilla (siglos XIV-XVI)
333 María Encarnación Martín López

Las inscripciones medievales del claustro de la catedral de Roda de Isábena (Huesca). Aproximación a su taller lapidario

\section{ISABEL MONTES ROMERO-CAMACHO}

Los archivos catedralicios y su importancia para los estudios prosopográficos. El deán Don Aparicio Sánchez, en el Archivo de la Catedral de Sevilla

\subsection{Gonzalo Oliva Manso}

La moneda en Castilla y León (1265-1284). Alfonso X, un adelantado a su tiempo.

4.73 Mariana Valeria Parma

Entre los signos del cielo y las voces de los hombres: La visión medieval del cielo y su representación apocalíptica

\section{Milagros Plaza Pedroche \\ Los maestres santiaguistas y su designación regia durante el} reinado de Juan I de Trastámara (1379-1390): La legitimación del proceso

521 Juan A. Prieto Sayagués

La profesión de las élites castellanas en los monasterios y conventos durante la Baja Edad Media

\section{EnRIQUe José RuIz PILARES}

La funcionalidad social de los inmuebles urbanos de las élites dirigentes bajomedievales: Reflexiones a partir de un caso de estudio (Jerez de la Frontera, España)

\section{Gilberto SORIANO Calvo}

Influencia de las redes nobiliarias en la expansión cristiana del siglo XII. El caso de Soria

Mohammed S. TawfiQ, AlmudenaArizaArmada, Atef Mansour Mohammad, Ahmed Ameen y Mervat Abd EL-HadyAbdEL-Latif A Historical and Numismatic Study of the Dinars of the Ghaznavid Sultan Mahmūd B. Sabuktakin at Nishapur

653 JOSÉ LUIS DE VILLAR IGLESIAS

Los aspectos económicos en la Batalla por el Magreb entre omeyas y fātimíes: El control del acceso al oro del Sudán Occidental

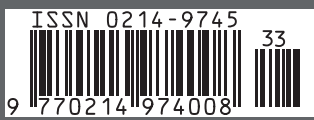




\section{3}

\section{ESPACIO,}

\section{TIEMPO}

Y FORMA

UกED

SERIE III HISTORIA MEDIEVAL

REVISTA DE LA FACULTAD DE GEOGRAFÍA E HISTORIA

\section{Libros · Books}

679 Bello León, Juan Manuel y ORTEgo Rico, Pablo, Los agentes fiscales en la Andalucía Atlántica a finales de la Edad Media: Materiales de trabajo y propuesta de estudio (ANA MARÍA RIVERA MEDINA)

683 Calleja Puerta, Miguel y Domínguez Guerrero, María Luisa (eds.), Escritura, notariado y espacio urbano en la Corona de Castilla y Portugal (siglos XII-XVII) (PALOMA CUENCA MuÑoz)

687 CASADO ALONSO, Hilario (coord.), Comercio, finanzas $y$ fiscalidad en Castilla (siglos XV-XVI) (ANA MARía RIVERA MEdINA)

691 Castro Correa, Ainoa y Rodríguez Sánchez, Manuel, Colección diplomática altomedieval de Galicia II. Documentación en escritura visigótica de la sede lucense (PALOMA CUENCA MUÑOZ)

695 García Fernández, Ernesto, García-Gómez, Ismael, Rodríguez FERNÁNDEZ, José, Urbanismo, patrimonio, riqueza y poder en Vitoria-Gasteiz a fines de la Edad Media e inicios de la Edad Moderna (ENRIQUE CANTERA MONTENEGRO)

699 LADERO QUESADA, Miguel Ángel, Ciudades de la España medieval. Introducción a su estudio (GISELA CORONADO SCHWINDT)

705 LADERo Quesada, Miguel Ángel, Los últimos años de Fernando el Católico 1505-1517 (CARLOS BARQuero GoÑI)

707 Martín GutiérRez, Emilio y Ruiz Pilares, Enrique José, El viñedo en Jerez durante el siglo XV. Un mercado de trabajo en torno al vino (ANa María Rivera MEDINA)

711 MONSALVO ANTÓN, José María, La construcción del poder real en la monarquía castellana (siglos XI-XV) (MARÍA Jesús FUENTE)

715 Pérez Rodríguez, Francisco Javier, Los monasterios del Reino de Galicia entre 1075 y 1540: De la reforma gregoriana a la observante (EnRIQue CANTERA Montenegro)

717 REIXACH SALA, Albert, Finances públiques i mobilitat social a la Catalunya de la Baixa Edat Mitjana. Girona, 1340-1440 (JuLIÁN DONADO VARA)

721 SÁNCHEZ SÁNCHEZ, Xosé M., Iglesia, mentalidad y vida cotidiana en la Compostela medieval (ENRIQUe CANTERA MONTENEGRO)

725 Val Valdivieso, M. ${ }^{a}$ Isabel del, Martín Cea y Juan Carlos, CARVAJAL de La Vega, David (coords.), Expresiones del poder en la Edad Media. Homenaje al profesor Juan Antonio Bonachía Hernando (José RAMÓN DÍAZ DE DURANA ORTIZ DE URBINA) 